\title{
Stent-grafting of the descending aorta: Value of early postinterventional computed tomographic control
}

Robert Bauernschmitt, MD, PhD, ${ }^{a}$ Bernhard Voss, MD, ${ }^{a}$ Albrecht Will, MD, ${ }^{b}$ Eva U. Schirmbeck, MD, MSc, ${ }^{a}$ Christian Firschke, MD, PhD, ${ }^{\mathrm{c}}$ Stefan Martinoff, MD, and Ruediger Lange, MD, PhD, ${ }^{\text {a }}$ Munich and Pfaffenhofen, Germany

See related editorial on page 1257.

tent-grafting of the descending thoracic aorta in patients with aneurysms or complicated type B dissections has emerged as a promising alternative to open surgical repair. ${ }^{1,2}$ Mortality and morbidity have been demonstrated to be lower than with open surgical procedures. ${ }^{3}$ Nevertheless, stent grafting must still be considered a developing technology, with indications, pitfalls, and safeguards yet to be defined.

\section{Clinical Summary}

A 49-year-old man had a history of chest trauma from a car accident 20 years before initial referral to our institution. Because he was symptom free and his clinical course was uneventful, he did not undergo any follow-up until chest radiography was performed for prolonged symptoms of influenza. The radiograph yielded a strong suspicion of a large, partially calcified aneurysm of the

From the Departments of Cardiovascular Surgery ${ }^{\mathrm{a}}$ and Radiology, ${ }^{\mathrm{b}}$ German Heart Center Munich, and the Department of Internal Medicine, Ilmtalklinik, ${ }^{\mathrm{c}}$ Pfaffenhofen, Germany.

Received for publication May 3, 2006; accepted for publication Aug 7, 2006.

Address for reprints: Eva U. Schirmbeck, MD, MSc, German Heart Center Munich, Department of Cardiovascular Surgery, Lazarettstrasse 36, 80636 Munich, Germany (E-mail: schirmbeck@dhm.mhn.de).

J Thorac Cardiovasc Surg 2006;132:e25-6

$0022-5223 / \$ 32.00$

Copyright $\odot 2006$ by The American Association for Thoracic Surgery doi:10.1016/j.jtcvs.2006.08.038 proximal descending thoracic aorta. Subsequent echocardiography and computed tomographic (CT) scan confirmed the diagnosis, showing an aneurysm with a maximum diameter of $8 \mathrm{~cm}$ distally at the smaller aortic curvature (Figure 1,a).

Subsequently, the patient underwent implantation of a thoracic stent graft (VALIANT; Medtronic AVE, Santa Rosa, Calif) without further delay. The decision to use a stent graft was made by three cardiac surgeons specializing in both aortic stent implantation and open procedures. Institutional review board approval was not required because stent-grafting is considered to fall under routine clinical procedures and not clinical studies. Coverage of the left subclavian artery was considered necessary to achieve a sufficient proximal neck. During the implantation, heparin was given (5000 IU) and not antagonized by protamine sulfate after the intervention. Procedural success was documented by postinterventional angiography showing complete exclusion of the aneurysm with prompt left carotid artery filling. Carotid and brachial pulses were perfectly palpable.

After extubation on the same day, the patient was in clinically stable condition, with no signs of malperfusion of the left arm or neurologic deficit. Per our policy, CT scan was performed on the first postoperative day. It confirmed perfect exclusion of the aneurysm (Figure $1, b$ ) but with a 2 -cm thrombus at the origin of the left carotid artery (Figure 1,c), most probably caused by partial overstenting of the vessel. To avoid severe neurologic complications, immediate surgical repair was elected.

The patient underwent median sternotomy and cardiopulmonary bypass. After $18^{\circ} \mathrm{C}$ core temperature was achieved, the aortic arch was opened under hypothermic circulatory arrest. The innominate artery was cannulated and perfused for brain protection and washout of possible additional small thrombi in the left carotid.

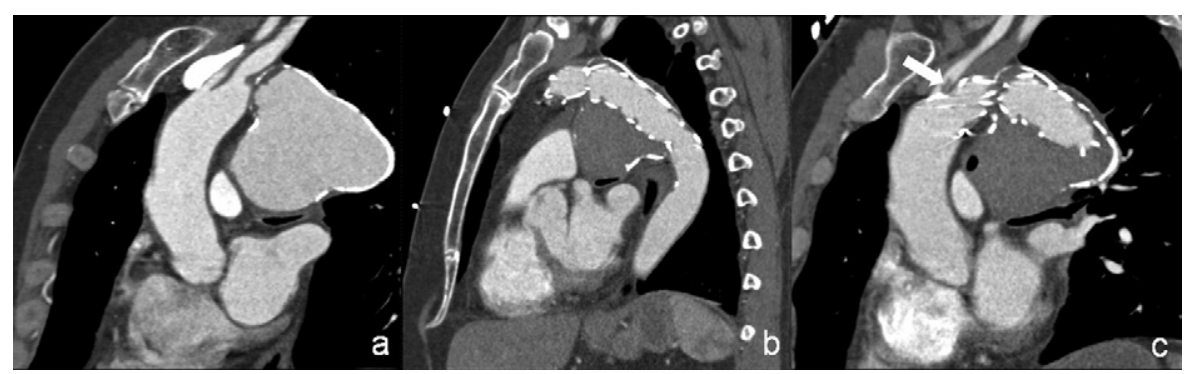

Figure 1. a, Preoperative computed tomographic scan shows partially calcified aneurysm of proximal descending thoracic aorta with maximum diameter of $8 \mathrm{~cm}$ distally at smaller aortic curvature. b, Computed tomographic scan on first postoperative day confirms perfect exclusion of aneurysm. c, Computed tomographic scan shows 2-cm thrombus (arrow) at origin of left carotid artery. 


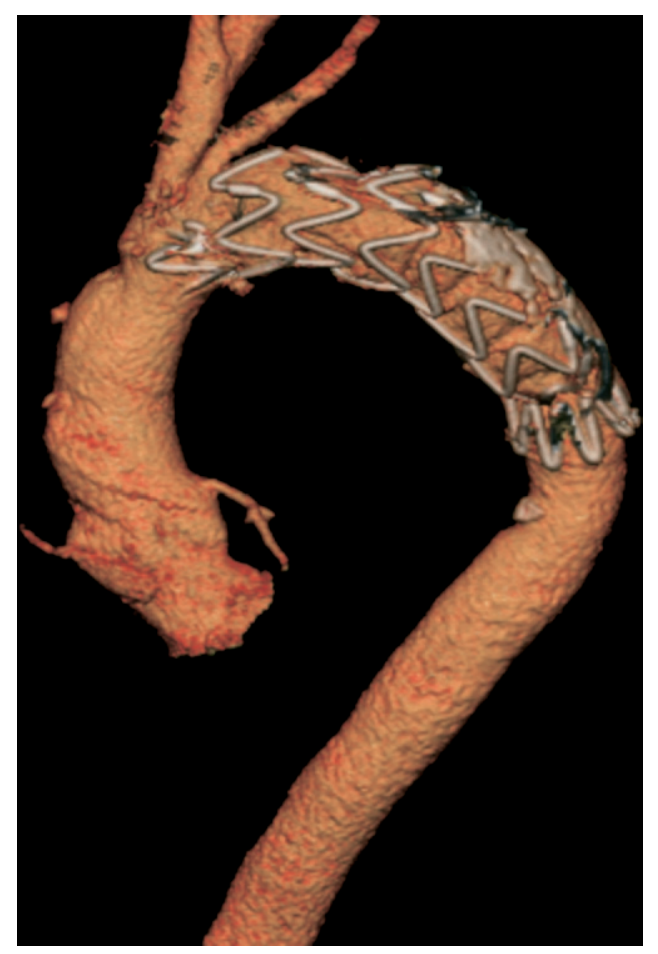

Figure 2. Computed tomographic scan in volume-rendering technique shows resected stent graft and resected thrombus to allow unobstructed flow into carotid artery.

The fabric of the stent graft was found to cover the origin of the left carotid artery for $2 \mathrm{~mm}$, with a fibrin thrombus adhering distally. After thorough removal of the thrombus, a part of the stent graft was resected in a semicircular manner to allow unobstructed flow into the carotid artery. To achieve secure fixation of the stent to the aortic wall, the proximal part of the stent was sewn to the inner aspect of the aortic arch with a running suture and several buttressed interrupted sutures. Overall circulatory arrest with antegrade cerebral perfusion lasted for 20 minutes.

The patient recovered uneventfully and was extubated hours after surgery. The postoperative result is shown in Figure 2.

\section{Discussion}

Because the technology of thoracic aortic stent-grafting is young, we still know little about the best treatment of early and late complications. Whereas late complications are usually due to graft migration and secondary endoleaks, early complications may be more dramatic, including major vessel rupture or occlusion. ${ }^{4}$ Emergency surgery is mandatory during these catastrophic events.

In the case presented here, the impending complication was indicated exclusively by CT findings, not by clinical symptoms. The therapeutic consequences may be controversial; watchful waiting and thrombolysis or stenting of the proximal carotid artery may be considered, carrying a high risk of fatal stroke. Carotidcarotid bypass and proximal ligation of the left carotid artery is another option, but with the drawback of leaving thrombotic material close to the aortic arch. Another possibility could be lateral thoracotomy, removal of the stent and partial arch, and descending aortic replacement in hypothermic circulatory arrest; this procedure can be technically demanding and is known to carry high risks of death and paraplegia. ${ }^{5}$ We chose open exploration of the aortic arch for several reasons: (1) the possibility of restoring physiologic flow patterns to the carotid artery, (2) complete removal of all thrombotic material, (3) secure fixation of the graft, thus preventing migration and secondary endoleaks, and (4) low operative risk with short hypothermic circulatory arrest and antegrade cerebral perfusion.

We concede that the appropriate choice of therapeutic strategies may be a matter of ongoing discussion. This case, however, demonstrates the value of postinterventional CT control after aortic stent-grafting to treat impending complications before they become clinically apparent.

\section{References}

1. Nienaber CA, Fattori R, Lund G, Dieckmann C, Wolf W, von Kodolitsch Y, et al. Nonsurgical reconstruction of thoracic aortic dissection by stent-graft placement. $N$ Engl J Med. 1999;340:1539-45.

2. Peterson BG, Longo GM, Matsumura JS, Kibbe MR, Morasch MD, Cardeira KR, et al. Endovascular repair of thoracic aortic pathology with custom-made devices. Surgery. 2005;138:598-605.

3. Riesenman PJ, Farber MA, Mendes RR, Marston WA, Fulton JJ, Mauro $\mathrm{M}$, et al. Endovascular repair of lesions involving the descending thoracic aorta. J Vasc Surg. 2005;42:1063-74.

4. Demers P, Miller DC, Mitchell RS, Kee ST, Sze D, Razavi MK, et al. Midterm results of endovascular repair of descending thoracic aortic aneurysms with first-generation stent grafts. J Thorac Cardiovasc Surg. 2004;127:664-73.

5. Brandt M, Hussel K, Walluscheck KP, Boening A, Rahimi A, Cremer J. Early and long-term results of replacement of the descending aorta Eur J Vasc Endovasc Surg. 2005;30:365-9. 